\title{
Purification and Characterization of Precipitating Antigens from Theileria parva
}

\author{
By B. A. AllsopP, G. G. WAGNER, K. P. MATTHEWS And \\ CATHERINE G. KARIAVU \\ East African Veterinary Research Organization, P.O Box 32, Kikuyu, Kenya
}

(Received 17 September 1976; revised 20 January 1977)

\begin{abstract}
SUMMARY
Precipitating antigens from Theileria parva have been partially purified. Two antigens from each of the schizont and piroplasm stages of the parasite were identified; the major antigens from the two stages shared the same specificity. The antigens showed considerable molecular heterogeneity, almost certainly a result of the preparative method, and they always contained large amounts of DNA. The piroplasm antigens were of parasite nuclear origin and the schizont antigens were probably of the same origin. The antigens were weakly antigenic, and the activity against them of humoral antibody from cattle immune to East Coast fever was low. These antigens do not appear to induce protection against East Coast fever.
\end{abstract}

\section{INTRODUCTION}

Theileria parva is a tick-transmitted protozoan parasite which causes East Coast fever (ECF) in cattle (Barnett, I963). During the course of the disease the parasite appears first as an intra-lymphocytic schizont, and later as an intra-erythrocytic piroplasm. Few animals recover spontaneously, but those which do are found to be immune to subsequent ECF challenge. The nature of this immunity is unknown.

Some work has already been done on the physical and immunological properties of T. parva antigens (Wagner et al., I974a, c). The aims of the present work were to obtain reasonable amounts of antigen of high purity for use in diagnostic serological tests, and to characterize the chemical nature of the antigens in the hope of distinguishing strains, of different immunogenic affinity, in vitro. At present the only method for distinguishing between such strains involves lengthy and costly cross-immunity trials in cattle (Radley et al., 1975).

\section{METHODS}

Organisms. Cattle (Bos taurus) are routinely infected at the East African Veterinary Research Organization (EAVRO) with tick-derived preparations (stabilates) of $T$. parva (Purnell et al., I973) by subcutaneous inoculation, in order to monitor the infectivity of the stabilates. Cattle infected in this manner were selected for the isolation of parasite material if they showed a severe response (Burridge et al., 1972). In practice this meant a parasitosis of 50 to $80 \%$ in lymph nodes and/or 30 to $50 \%$ in the erythrocytes.

The Muguga strain of T. parva has been maintained at EAVRO since its first isolation (Brocklesby, Barnett \& Scott, 196I), and most of our material came from animals infected with this strain. We occasionally obtained, for comparison, immunologically heterologous material from cattle infected with isolates ( $T$. parva Aitong and Kiambu 4; Radley et al., 1975) originating in other parts of Kenya. 
Solutions. Balanced salts solution (BSS) was prepared in the same way as Hank's BSS (Hanks \& Wallace, 1949) with the omission of glucose and phenol red and the addition of $\left(\mathrm{g}^{-1}\right)$ : EDTA, $2 \cdot 0$; penicillin, $0 \cdot 12$; and streptomycin, $0 \cdot 2$. Phosphate-buffered saline (PBS) was prepared by mixing equal volumes of $0.15 \mathrm{M}$-phosphate buffer ( $\mathrm{pH} 7 \cdot 2$ ) and $0.15 \mathrm{M}$-saline.

Immunodiffusion tests. Precipitins were detected on Ouchterlony plates [I \% (w/v) agarose] as described by Wagner et al. (I974a,c). Very close spacing (I $\mathrm{mm}$ ) between the wells $(6 \mathrm{~mm}$ diam.) was necessary for reliable production of precipitin lines.

Antisera. All antisera were stored at $-25{ }^{\circ} \mathrm{C}$ unless used immediately. Anti-ECF sera were obtained from cattle which had survived a severe ECF infection induced by the inoculation of T. parva-infected stabilate material (Wagner et al., 1975). Sera were collected 60 days after the primary infection, approximately I month after recovery; those sera giving good immunodiffusion reactions were selected for routine use.

Three control antisera were prepared as follows. (i) Cells were teased from a fragment of pre-scapular lymph node obtained from a clinically normal bovine. Approximately $4 \times 10^{8}$ cells were washed three times in PBS, and then resuspended in an equal volume of PBS and disrupted by passage through a French pressure cell (American Instrument Co., Silver Spring, Maryland, U.S.A.) using a $25.4 \mathrm{~mm}$ diam. piston at a pressure of $2.8 \times 10^{7} \mathrm{~Pa}$. The disrupted material was centrifuged $(5000 \mathrm{~g} ; 20 \mathrm{~min})$, the supernatant fluid was emulsified in an equal volume of Freund's complete adjuvant, and half the emulsion was inoculated subcutaneously at multiple sites into each of two rabbits. The rabbits received a similar inoculation I week later. Two weeks after the second inoculation, the rabbits were bled and the sera were pooled for use.

(ii) A cell-free extract of clinically normal bovine erythrocytes was prepared by the French pressure cell method described by Wagner et al. (I974c). Approximately $20 \mathrm{mg}$ protein was emulsified in Freund's complete adjuvant and inoculated into each of two rabbits as above. Five booster injections were given at approximately ro day intervals and the animals were bled Io days after the last injection. The sera were pooled for use.

(iii) Normal bovine serum, representing approximately I50 mg protein, was emulsified in an equal volume of Freund's complete adjuvant and inoculated into each of two rabbits as above. At approximately 10 day intervals the rabbits received three booster injections of normal bovine serum fractions [broadly corresponding to $\gamma, \beta$ and $\alpha$ globulins (peaks I, 2 and 3)], prepared by DEAE Sephadex A25 chromatography (Tris/ $\mathrm{HCl}, \mathrm{pH} 8 \cdot 6$, concentration gradient 0.01 to $0.7 \mathrm{M}$ ) as described by Duncan et al. (1972). Each booster dose consisted of approximately $10 \mathrm{mg}$ of pooled, concentrated globulin fractions. Ten days later the rabbits received a final booster of whole serum similar to the initial injection. The rabbits were bled after a further 10 days and the sera were pooled for use. This dose schedule was adopted because ultimately a better immunological response to all the serum components can be achieved if the immune system has to deal with a smaller number of components at any one time.

Schizont cell-free extract (CFE) preparation. Lymph nodes were taken from infected animals and examined microscopically; those showing maximum schizont infection were selected for treatment. Mesenteric nodes were not usually used.

Initially a variety of techniques was used to obtain free parasitized cells for the preparation of schizont CFE. All these techniques involved subdivision of lymph nodes, followed by stirring with a large volume of BSS, and filtration through gauze to produce a suspension of single cells. Subdivision methods tried were: chopping with scissors; mincing in a domestic meat mincer; disintegrating with a Silverson mixer (Silverson, Tower Bridge Road, London $\mathrm{SEI}$ ); and emulsifying for $5 \mathrm{~s}$ in an MSE Ato-Mix blender. However, the yields of antigen 
were so low that purification at the cellular level was abandoned and we concentrated on subsequent purification at the molecular level.

Lymph nodes were freed from connective tissue and weighed, before being minced in a domestic meat mincer, followed by mixing with BSS ( $\mathrm{I}: \mathrm{I}, \mathrm{w} / \mathrm{v})$ and treatment in an Ato-Mix blender $(3 \times 10 \mathrm{~s})$. After straining through gauze, the mixture was diluted $\mathrm{I}: 2(\mathrm{v} / \mathrm{v})$ with BSS and sonicated at $4{ }^{\circ} \mathrm{C}$ (IO $\times$ I min, with $30 \mathrm{~s}$ breaks for cooling; MSE I $50 \mathrm{~W}$ ultrasonic disintegrator MK2). After further straining through gauze, crude schizont CFE was prepared by centrifugation ( $40000 \mathrm{~g} ; \mathrm{I} \mathrm{h} ; 4{ }^{\circ} \mathrm{C}$ ). Any lipid collecting above the supernatant fluid was removed, and the supernatant fluid was concentrated (ultrafiltration through Visking tubing under vacuum) to about $100 \mathrm{mg}$ protein $\mathrm{ml}^{-1}$, as determined by absorbance at 260 and $280 \mathrm{~nm}$, followed by a final centrifugation $\left(200000 \mathrm{~g} ; 2 \mathrm{~h} ; 4{ }^{\circ} \mathrm{C}\right)$.

For comparison we occasionally made batches of schizont CFE from lymphoblastoid cell culture material infected with $T$. parva (Malmquist, Nyindo \& Brown, 1970). Packed washed cells were suspended in BSS $(1: 2, v / v)$ and sonicated as above; schizont CFE was then obtained by centrifugation $\left(200000 \mathrm{~g} ; \mathrm{I} \mathrm{h} ; 4{ }^{\circ} \mathrm{C}\right)$. Schizont-infected tissue culture cells appeared to be completely disrupted by sonication for I min, since no intact cells or schizonts were visible microscopically, but no detectable antigen was released. We performed sonication trials for various periods, and chose the treatment described above which gave reproducible release of both major and minor antigens.

Piroplasm cell-free extract preparation. Blood was taken directly from the jugular vein of an infected animal into an equal volume of cold BSS, and then centrifuged ( $2000 \mathrm{~g}$; I0 min; $4{ }^{\circ} \mathrm{C}$ ). The supernatant fluid and buffy coat cells were removed by aspiration, and the red cells were made up to the initial blood volume with BSS and recentrifuged. After four washes the red cells were suspended in BSS $(\mathrm{I}: 2, \mathrm{v} / \mathrm{v})$ and sonicated in $50 \mathrm{ml}$ batches for $30 \mathrm{~s}$ at $4{ }^{\circ} \mathrm{C}$. This produced 90 to $95 \%$ lysis, as determined by cell counting with a Coulter counter (model ZBI; Coulter Electronics, Hialeah, Florida, U.S.A.). Unlysed red cells were removed by centrifugation ( $1300 \mathrm{~g} ; \mathrm{I} 5 \mathrm{~min} ; 4{ }^{\circ} \mathrm{C}$ ) and the supernatant fluid was recentrifuged $(23000 \mathrm{~g}$; $\left.\mathrm{I} \mathrm{h} ; 4{ }^{\circ} \mathrm{C}\right)$. The resulting supernatant fluid contained only cell debris and was discarded. The sediment, consisting of debris, whole piroplasms and a few intact red cells, was suspended in a small volume of BSS (less than $100 \mathrm{ml}$ for 31 blood) using a glass tissue grinder. When this suspension was centrifuged $(40000 \mathrm{~g}$; Io $\mathrm{min})$, it yielded three distinct layers which could be separated with a spatula. The upper flocculent whitish layer was debris; the middle brown-grey layer was mainly piroplasms with some debris; the bottom layer was a red button of intact red cells with a few piroplasms. The piroplasm layer was removed, resuspended in BSS with a glass tissue grinder and centrifuged as before. This procedure was repeated hree times, by which time the piroplasm layer appeared to be almost pure, as judged by microscopical examination of Giemsa-stained smears.

The piroplasms were suspended in BSS $(\mathrm{I}: 2, \mathrm{v} / \mathrm{v})$ and then sonicated at $4{ }^{\circ} \mathrm{C}(\mathrm{I} 5 \times \mathrm{I} \mathrm{min}$, with $30 \mathrm{~s}$ breaks for cooling); piroplasm CFE was obtained by centrifugation (200000 $\mathrm{g}$; I h; $4^{\circ} \mathrm{C}$ ). Piroplasms, examined microscopically, did not appear to be affected by sonication for I min and no detectable antigen was released. We performed sonication trials for various periods, and chose the treatment described above which gave reproducible release of both major and minor antigens.

Isoelectric focusing. This was conducted in polyacrylamide gel slabs as described by Allsopp \& Matthews (I975). Protein was stained with Coomassie brilliant blue (0. I I \%, w/v) dissolved in methanol $(33 \%, \mathrm{v} / \mathrm{v})$ containing sulphosalicylic acid $(3.3 \%$, w/v) and trichloroacetic acid ( $\mathrm{I} \cdot 0 \%, \mathrm{w} / \mathrm{v})$. Gels were stained for $15 \mathrm{~min}$ at $60{ }^{\circ} \mathrm{C}$, followed by destaining in acetic acid/ethanol/water ( $1: 3: 8$, by vol.). Staining for nucleic acid was with methylene blue 
$(0.02 \%, w / v)$ in $0.01 \mathrm{M}$-Tris/acetic acid, $\mathrm{pH} 8.3$ for $2 \mathrm{~h}$ at room temperature, followed by destaining in the same buffer. Antigen was located in gel slabs after focusing by cutting a $\mathrm{I} \mathrm{cm}$ wide strip, parallel to the $\mathrm{pH}$ gradient. This strip was sectioned into segments $2.5 \mathrm{~mm}$ wide, each of which was forced through a 17 gauge needle into a well on an Ouchterlony plate.

Isoelectric focusing was also conducted on a preparative scale in a I Io $\mathrm{ml}$ sucrose density gradient contained in a density gradient electrophoresis column (ISCO model 630, Instrumentation Specialties Co., Lincoln, Nebraska, U.S.A.).The density gradient (sp.gr. I 25 to I $\cdot$ I0) contained $2 \%(\mathrm{w} / \mathrm{v})$ carrier Ampholytes (LKB) and 2 M-urea. The sample was incorporated in the central part of the gradient to avoid contact with the electrode solutions, which contained $0.9 \%(\mathrm{v} / \mathrm{v})$ ethanolamine (cathode) or $0.5 \%(\mathrm{v} / \mathrm{v})$ phosphoric acid (anode). The lower electrode solution was of sp.gr. I 30 , and the upper of sp.gr. I 00 . The density steps between the gradient and the electrode solutions were necessary in order to prevent mixing. The column was thermostatically controlled at $10{ }^{\circ} \mathrm{C}$ and focused at constant power $(<2 \mathrm{~W})$ until the current was constant, usually after 48 to $72 \mathrm{~h}$ depending on the $\mathrm{pH}$ range in use. The column was then emptied through an ultraviolet monitor and fractions were collected. The $\mathrm{pH}$ gradient was determined manually.

Polyacrylamide gel electrophoresis was conducted as described by Allsopp \& Matthews (I975), using the discontinuous $\mathrm{pH}$ buffer system previously used or a continuous $\mathrm{pH}$ system (Allen, 1974). Gels were stained for protein or nucleic acid as above.

Ion exchange chromatography was done on both DEAE-cellulose (Whatman DE 32) and DEAE Sephadex A50. Columns were stabilized with citrate/phosphate buffer (McIlvaine, I92I), $\mathrm{pH} 7 \cdot 6, I=0.258 \mathrm{M}$, and eluted after sample application with a linear $\mathrm{pH}$ gradient of the same buffer ( $\mathrm{pH}_{7} \cdot 6$ to $5 \cdot 2, I=0.258$ to $0.139 \mathrm{M}$ ).

Gel permeation chromatography was performed on Sephadex G200 and Sepharose 2B. Columns were stabilized and eluted at constant flow rate with $0.05 \mathrm{M}$-Tris $/ \mathrm{HCl}$ buffer, $\mathrm{pH} 8.4$, containing sodium azide $(0.02 \%, \mathrm{w} / \mathrm{v})$. The relationship between the elution behaviour of species and their molecular weights was calculated using data published by the gel manufacturers.

Assay for nucleic acids. Fractions from Sephadex and Sepharose chromatography were assayed for DNA by the method of Richards (1974) and for RNA by the method of Ceriotti (I955). Before estimation, the nucleic acids were extracted, and protein precipitated, by two separate extractions with $5 \%(\mathrm{w} / \mathrm{v})$ trichloroacetic acid at $90{ }^{\circ} \mathrm{C}$ for $20 \mathrm{~min}$ (Burton, 1968 ). RNA determinations were corrected for the known contribution of DNA to colour formation in the Ceriotti test.

\section{RESULTS}

\section{Immunodiffusion tests on crude antigens}

Precipitin lines obtained with schizont and piroplasm CFE were always weak, the former more so than the latter. This subjective assessment is based on the following observations. Plates were always examined on a dark ground viewer, otherwise lines were not visible. Only very active samples gave visible lines on Ouchterlony plates with $6 \mathrm{~mm}$ spacing between $6 \mathrm{~mm}$ diam. wells; no reactions were seen with $10 \mathrm{~mm}$ spacing between $6 \mathrm{~mm}$ wells. It was not possible to produce visible precipitin lines by immunoelectrophoresis or Laurell rocket electrophoresis.

Because of the poor precipitin activity, we were not able to quantify the antigen reproducibly by normal serial dilution. Relative amounts of antigen were estimated by visual appraisal of precipitin lines (histograms in Figs $\mathrm{I}$ to 3 ).

Schizont CFE from both infected lymph nodes and tissue culture material contained two 

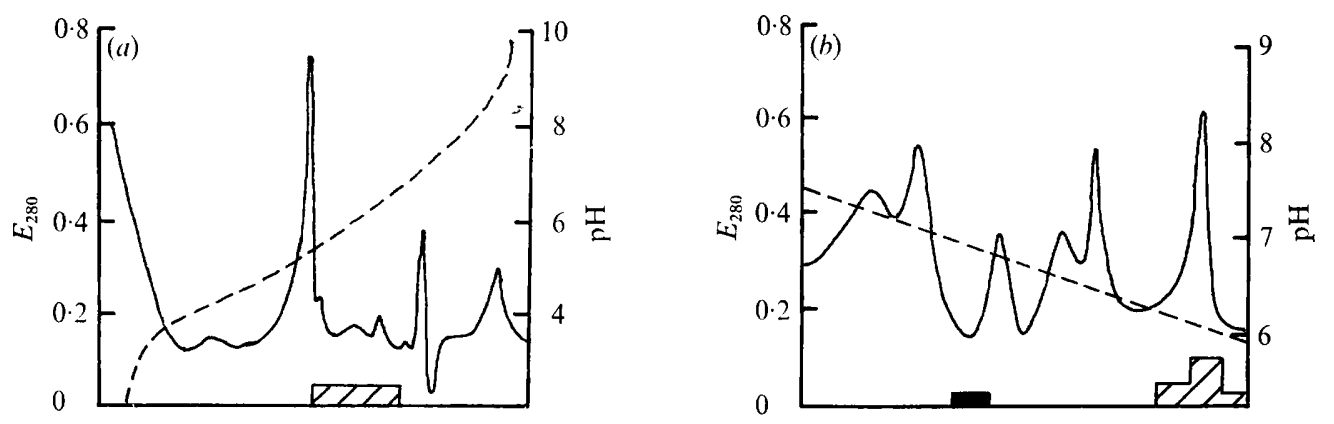

Fig. I. Protein elution profile (-) and pH of fractions (--) of T. parva schizont CFE: (a) after isoelectric focusing in a column stabilized by a sucrose density gradient; the gradient incorporated Ampholytes of $\mathrm{pH}$ range 3 to 10 , and $2 \mathrm{M}$-urea; $(b)$ after ion exchange chromatography on a column of $\mathrm{DE} 32$ cellulose; elution was with a linear gradient, $\mathrm{pH} 7.6$ to $5 \cdot 2$, in citrate/phosphate buffer. Antigen recovery is shown by the histograms: $\mathrm{M}_{\mathrm{J}} \mathrm{S},\|/\| ; \mathrm{M}_{\mathrm{N}} \mathrm{S}$,

antigens, designated (in respect of their activities on plates) as major $\left(M_{J} S\right)$ and minor $\left(M_{N} S\right)$ schizont antigens. Each of these appeared to have the same specificity irrespective of their source. Because the amount of starting material available from tissue culture was limited, subsequent purification work was performed on infected lymph node CFE.

Piroplasm CFE, which was generally more active than the schizont material, also contained two antigens, designated as major $\left(\mathrm{M}_{J} \mathrm{P}\right)$ and minor $\left(\mathrm{M}_{\mathrm{N}} \mathrm{P}\right)$ piroplasm antigens on the basis of their observed activities.

We did not observe any specificity differences between $T$. parva Muguga material and material from the other isolates, in either schizont or piroplasm CFE.

\section{Separation of crude antigens}

Antigenic activity was recovered with difficulty from gels after isoelectric focusing. The $\mathrm{pH}$ ranges were 5.8 to 6.2 for schizont antigen, and $7 \cdot 4$ to 8.2 for piroplasm antigen. In each case only the major antigen could be located. It was not possible to identify, after staining, any discrete protein line in the region where antigenic activity was found.

When schizont CFE was subjected to isoelectric focusing in sucrose density gradients, considerable difficulties were encountered because of precipitation of material at or around $\mathrm{pH} 5 \cdot 2$. The precipitate appeared to adsorb the antigen, since no activity was found in the expected 5.8 to $6 \cdot 2 \mathrm{pH}$ region, and some activity was subsequently found in the precipitate after redissolution. This problem persisted despite changes of the Ampholyte concentration and electrode configuration, but was partially resolved by incorporating $2 \mathrm{M}$-urea in the gradient. Under these conditions the material at $\mathrm{pH} 5.2$ remained in solution, and $\mathrm{M}_{\mathrm{J}} \mathrm{S}$ was recovered over the $\mathrm{pH}$ range $5 \cdot 3$ to $6 \cdot 7$ (Fig. I $a$ ). The activity of antigen prepared in this way was low, and $\mathrm{M}_{\mathrm{N}} \mathrm{S}$ was not recovered.

The best results for schizont CFE on ion exchange chromatography using DE 32 cellulose are shown in Fig. $I(b) . M_{J} S$ and $M_{N} S$ were eluted over the $\mathrm{pH}$ ranges 5.9 to 6.3 and 6.8 to 7.0 respectively. Although complete separation of the two antigens was achieved, activities were not high; $\mathrm{M}_{\mathrm{N}} \mathrm{S}$ particularly was barely detectable. Unfortunately larger loads of starting material spread the range over which the antigens were eluted.

When estimating protein by absorbance at 260 and $280 \mathrm{~nm}$, fractions which had high antigenic activities showed high absorbances at $260 \mathrm{~nm}$. Fractions from gel chromatography were therefore assayed for DNA and RNA in addition to examination for antigenic activity. 

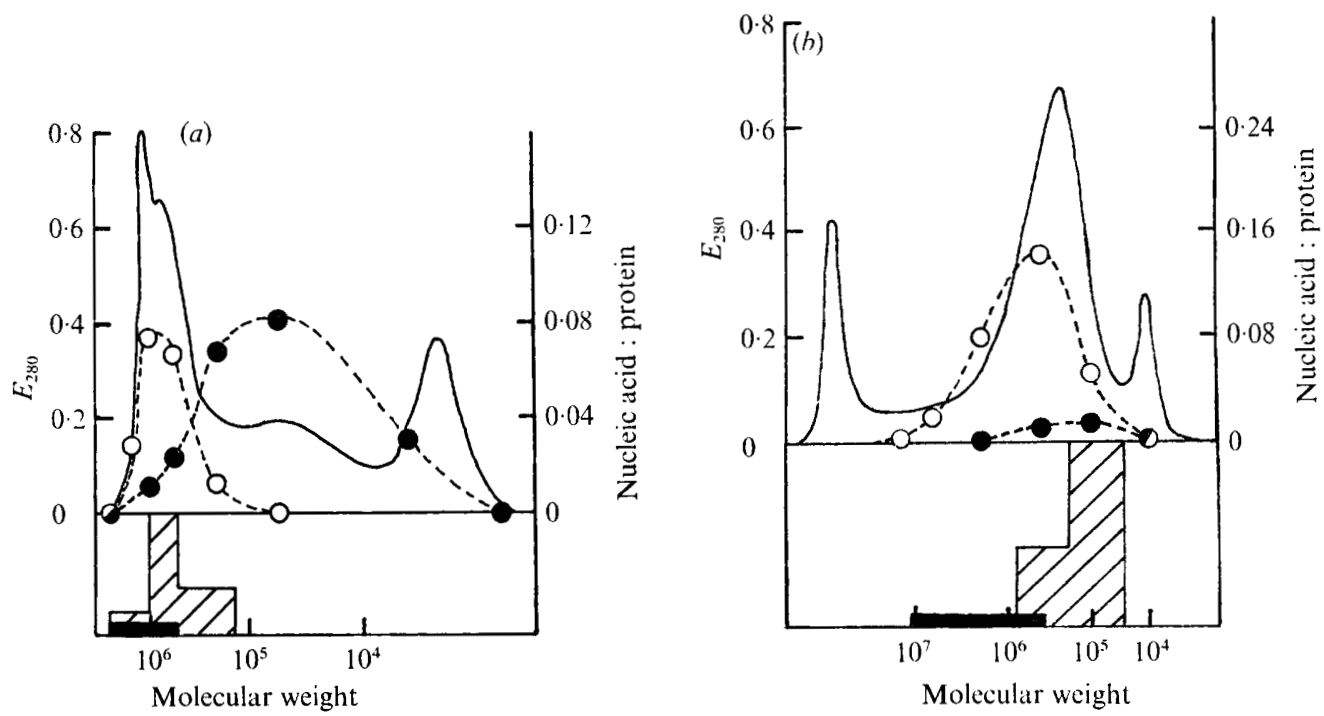

Fig. 2. Protein elution profile (-) and nucleic acid content of fractions (---), after gel permeation chromatography of $T$. parva schizont CFE: (a) on a column of Sephadex G200; (b) pooled antigencontaining fractions from $(a)$ on a column of Sepharose 2B. O, DNA;, RNA. Antigen recovery is shown by the histograms: $M_{J} S, I / / / ; M_{N} S$,
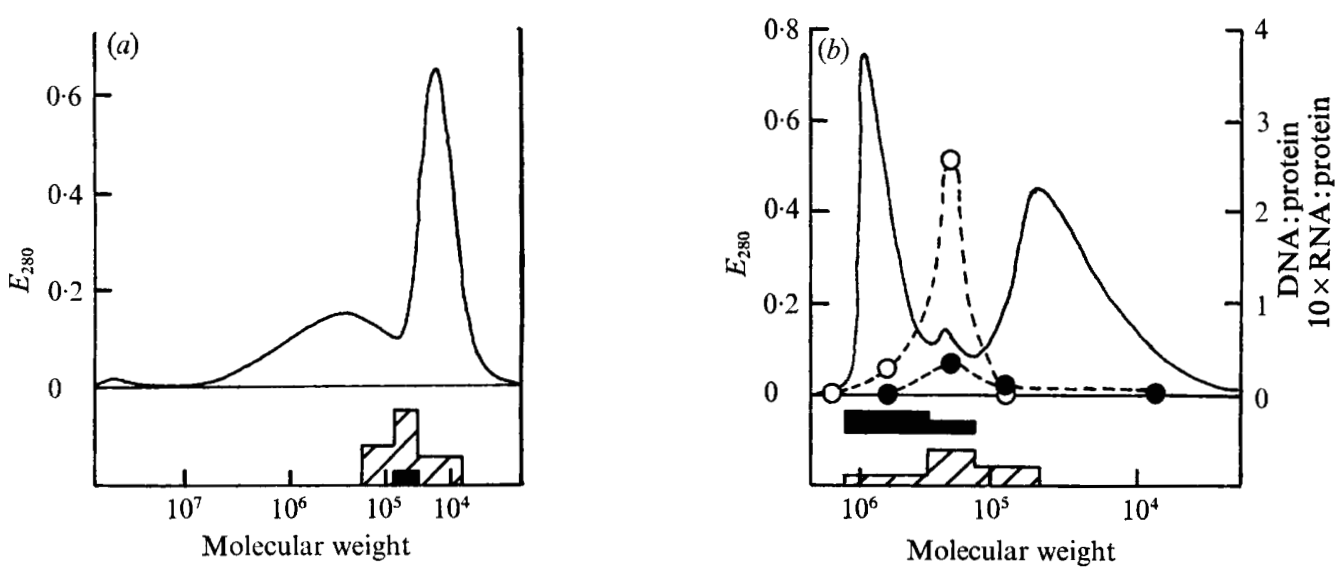

Fig. 3. Protein elution profile (-) and nucleic acid content of fractions (---), after gel permeation chromatography of $T$. parva piroplasm CFE: (a) on a column of Sepharose $2 \mathrm{~B}$; (b) on a column of Sephadex G200. (O) DNA, (@) RNA. Antigen recovery is shown by the histograms: $\mathbf{M}_{\mathbf{J}} \mathbf{P}, \mathbf{I} / 1 /$; $\mathbf{M}_{\mathrm{N}} \mathbf{P}, \mathbf{m}$.

When schizont CFE was chromatographed on Sephadex G200, the antigens were eluted in, or closely following, the void volume, suggesting they had a molecular weight range of $10^{5}$ to $10^{6}$ (Fig. 2a). There was partial discrimination between major and minor components, but no separation. The DNA content and antigenic activity of eluted fractions were roughly parallel; RNA was eluted after the antig en. The maximum DNA: protein ratio was 0.076 ; the DNA:RNA ratio in this fraction was $6 \cdot 3$. 


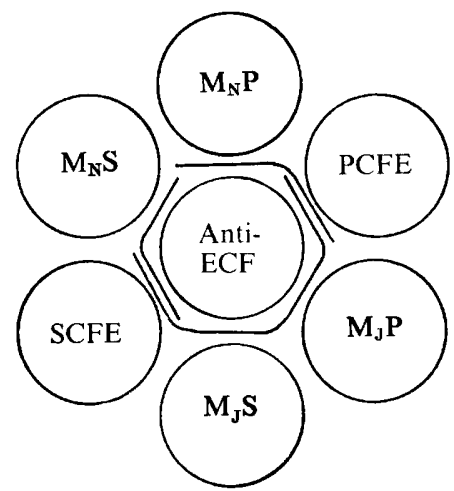

Fig. 4. Diagram indicating the precipitin pattern obtained on an Ouchterlony plate with T. parva schizont (S) and piroplasm (P) CFE and antigens separated from them, against a bovine anti-ECF serum.

All the antigen-containing fractions were pooled, concentrated and passed through Sepharose $2 \mathrm{~B}$ (Fig. $2 b$ ). This resulted in separation of the two components, $\mathbf{M}_{\mathbb{N}} \mathrm{S}$ being eluted over a molecular weight range of $4 \times 10^{5}$ to $10^{7}$, and $\mathrm{M}_{\mathrm{J}} \mathrm{S}$ over a range of $2 \times 10^{4}$ to $8 \times 10^{5}$. The activity of $\mathrm{M}_{\kappa} \mathrm{S}$ was always low, but it was recovered consistently. The activity of $M_{J} S$ purified by this technique was higher than that found with any of the other methods used. The nucleic acid analyses gave results similar to those obtained after Sephadex G200 chromatography, except that the DNA and antigen maxima did not coincide exactly. The maximum DNA: protein ratio was 0.14 , with a corresponding DNA:RNA ratio of $14^{\circ} 0$.

When piroplasm CFE was subjected to gel permeation chromatography, Sepharose $2 \mathrm{~B}$ failed to separate $\mathbf{M}_{\mathrm{J}} \mathbf{P}$ and $\mathbf{M}_{\mathrm{N}} \mathbf{P}$ (Fig. $3 a$ ). Reasonably good separation was achieved on Sephadex G200 (Fig. 3 b), MJP being eluted over a molecular weight range of $4 \times 10^{4}$ to $10^{6}$, and $\mathrm{M}_{\mathrm{N}} \mathrm{P}$ over a range of $10^{5}$ to $10^{6}$. The considerable overlap of molecular weight between the two antigens precluded complete separation. Both DNA and RNA content paralleled antigenic activity (Fig. $3 b$ ), but the amounts of RNA found were very small. The most active $\mathrm{M}_{\mathrm{J}} \mathrm{P}$ fraction also had the maximum DNA:protein ratio, $2 \cdot 6$, with a corresponding DNA: RNA ratio of $76 \cdot 5$.

\section{Properties of partially purified antigens}

We examined both schizont and piroplasm antigen fractions by isoelectric focusing and electrophoresis on polyacrylamide gels in the hope of achieving further characterization. The antigens did not focus into discrete lines during isoelectric focusing, and did not give sharp lines (in either buffer system used) after electrophoresis. In all experiments the antigens migrated in the gel, spread over a diffuse region, and stained for both protein and nucleic acid.

All our schizont antigen preparations reacted strongly on Ouchterlony plates with rabbit antisera to both normal bovine serum proteins and normal bovine lymphocytes. By comparison, some of our piroplasm antigen preparations reacted only faintly, or not at all, with a rabbit antiserum to normal bovine erythrocyte material.

Because of the narrow well spacing required for the immunodiffusion reactions it was difficult to be certain of the identity relationship between adjacent precipitin lines. After studying many plates we concluded that $M_{J} P$ and $M_{J} S$ shared the same antigenic specificity, but $M_{N} S$ and $M_{N} P$ differed from one another and from the major component (Fig. 4). 


\section{DISCUSSION}

The results of the immunodiffusion reactions were in general agreement with the estimated molecular weight data for the antigens. Thus $M_{J} S$ and $M_{J} P$ appeared to share the same antigenic specificity, and were eluted from Sepharose $2 \mathrm{~B}$ over similar molecular weight ranges $\left(2 \times 10^{4}\right.$ to $8 \times 10^{5}$ for $M_{J} S$ and $10^{4}$ to $2 \times 10^{5}$ for $\left.M_{J} P\right)$. Similarly, $M_{\kappa} S$ and $M_{N} P$ appeared to have specificities differing both from one another and from that of the major components (molecular weights from Sepharose $2 \mathrm{~B}_{3} \times 10^{5}$ to $7 \times 10^{6}$ for $\mathrm{M}_{\mathrm{N}} \mathrm{S}, 3 \times 10^{4}$ to $7 \times 10^{4}$ for $\mathrm{M}_{\mathrm{N}} \mathrm{P}$ ).

The most striking feature of the antigens, of both schizont and piroplasm origin, was their considerable molecular heterogeneity. This heterogeneity was particularly evident from the wide range of molecular weight exhibited on gel chromatography, the wide range of $\mathrm{pI}$ exhibited on isoelectric focusing, the absence of discrete focused lines after isoelectric focusing on polyacrylamide gels, and the failure of two different stacking systems to give sharp lines after polyacrylamide gel electrophoresis.

The wide variety of purification techniques used in this study failed to produce a schizont antigen free from normal bovine contaminants. The molecular heterogeneity of the antigen was obviously the major factor which frustrated further purification by purely physical methods and which also precluded the possibility of demonstrating small strain-specific differences. For the piroplasm material the difficulty was lessened by the possibility of performing the initial purification at the cellular level. Even so, the molecular heterogeneity of the antigen was still very pronounced.

Sonication of a duration normally expected to be sufficient to release soluble cytoplasmic constituents failed to release detectable amounts of schizont or piroplasm antigen. This forced us to use extended sonication periods, and the obvious deduction was that we were thereby suspending normally insoluble antigenic material by physical fragmentation. This would inevitably have led to a heterogeneous preparation.

It has previously been suggested (Wagner et al., I $974 a, b$ ) that the antigens are portions of parasite membrane. However, our nucleic acid determinations suggest that the antigens are fragmented parasite nucleic material.

The DNA:protein ratio of 2.6 for piroplasm antigen was well within the range normally expected for purified chromatin (Bonner et al., 1968), with no possibility that the DNA could be of bovine origin. The DNA:protein ratio of 0.14 for schizont antigen was in the range expected for crude chromatin. We would expect that bovine and parasite nuclear material would behave similarly during sonication, and would therefore be difficult to separate subsequently by physical means. This could explain why we were not able to obtain preparations of schizont antigen free from normal bovine activity.

Previous work showed that inoculation of partially purified schizont or piroplasm antigen into cattle produced a specific immune response, but the immune status of the animal with respect to subsequent ECF challenge was completely unaltered (Wagner et al., I $974 b$ ). When cattle are inoculated with infective $T$. parva material, schizonts are not detectable in lymph nodes in less than 5 days (Radley et al., 1974). If the cattle are immune, schizonts either do not appear at all, or appear transiently and in small numbers (Burridge et al., 1972). Piroplasms only develop in immune animals when the immunity is declining (A. S. Young, personal communication). The form and location of the parasite during the first 4 days after inoculation (the pre-schizont stage) are unknown, and the immune mechanism operating against the parasite during this period is also unclarified. However, the protective mechanism does destroy any schizonts and piroplasms which are able to develop, thus releasing parasite nuclear material, to which a normal humoral immune response can subsequently be raised. 
We may postulate, therefore, that the humoral activity against schizont and piroplasm nuclear material, found in immune antisera, arises purely as a secondary effect after the unidentified immune mechanism has operated against the parasite. We must conclude that precipitating antigens of $T$. parva are not involved in the all-important immune mechanism which is responsible for immunity to ECF. The weakness of the observed humoral activity is consistent with it arising as a secondary effect, and is to be expected in view of the poor antigenicity of nucleoproteins.

The humoral activity could arise either after direct destruction of schizonts and piroplasms, or because the schizont and piroplasm antigens are shared by the pre-schizont stage. If the former is the correct explanation it is difficult to understand the lack of reactivity to parasite cytoplasmic constituents, hence the latter explanation seems more probable.

We thank the staff of the UNDP/FAO Immunological Research on Tick-borne Cattle Diseases and Tick Control Project, and of the British Ministry of Overseas Development Research Project R2844, for parasite material. Specific thanks go to Mr C. G. D. Brown, Dr T. T. Dolan, and Dr A.S. Young. We also thank the acting Director, EAVRO, for permission to publish this paper.

G. G. Wagner is seconded from the United States Department of Agriculture, and K. P. Matthews is seconded from the British Ministry of Agriculture, Fisheries and Food.

\section{REFERENCES}

Allen, R. C. (1974). Electrophoresis and Isoelectric Focusing in Polyacrylamide Gel, pp. I05-I I3. Edited by R. C. Allen and H. R. Maurer. Berlin and New York: de Gruyter.

Allsopp, B. A. \& Matthews, K. P. (1975). Studies of lactate dehydrogenase of Mycoplasma mycoides var. mycoides. Journal of General Microbiology 88, 58-64.

BARNETT, S. F. (I963). The biological races of the bovine Theileria and their host-parasite relationship. In Immunity to Protozoa. Edited by P. G. Garnham, E. A. Pierce and I. Roitt. Oxford: Blackwell Scientific Publications.

BONNER, J. ET AL. (1968). Criteria of purity for isolated chromatin. Methods in Enzymology $12 \mathbf{B}, 7$.

Brocklesby, D. E., BarnetT, S. F. \& ScotT, G. R. (I96I). Morbidity and mortality rates in East Coast fever (Theileria parva infection) and their application to drug screening procedures. British Veterinary Journal II7, 529-53I.

Burridge, M. J., Morzaria, S. P., Cunningham, M.P. \& Brown, C. G. D. (I972). Duration of immunity to East Coast fever. Parasitology 64, 5 I I-5 I 5 .

Burton, K. (1968). Preparation of nucleic acid solutions for estimation. Methods in Enzymology 12B, 164.

CERIOTTI, G. (I955). Determination of nucleic acids in animal tissue. Journal of Biological Chemistry 214, $59-70$.

Duncan, J. R., Wilkie, B. N., Hiestand, F. \& Winter, A. J. (I972). The serum and secretory immunoglobulins of cattle: characterization and quantitation. Journal of Immunology ro8, 965-976.

HANKS, J. H. \& WALlaCE, R. E. (I949). Relation of oxygen and temperature in the preservation of tissues by refrigeration. Proceedings of the Society for Experimental Biology and Medicine 71, I96-200.

Malmquist, W. A., Nyindo, M. B. A. \& Brown, C. G. D. (1970). East Coast fever: cultivation in vitro of bovine spleen cell lines infected and transformed by Theileria parva. Tropical Animal Health and Production 2, 139-I 45.

McIlvaine, T. C. (1921). A buffer solution for colorimetric comparison. Journal of Biological Chemistry 49, I 83-186.

Purnell, R. E., Brown, C. G. D., Cunningham, M. P., Burridge, M. J., Kirimi, I. M. \& Ledger, M. A. (I973). East Coast fever, correlation between the histology and infectivity of Theileria parva developing in the tick vector. Parasitology 66, 539-544.

Radley, D. E., Brown, C. G. D., Burridge, M. J., Cunningham, M. P., Pierce, M. A. \& Purnell, R. E. (1974). East Coast fever: quantitative studies of Theileria parva in cattle. Experimental Parasitology 36, 278-287.

Radley, D. E., Brown, C. G. D., Burridge, M. J., Cunningham, M. P., Kirimi, I. M., Purnell, R. E. \& Young, A. S. (1975). East Coast fever: 1. Chemoprophylactic immunization of cattle against Theileria parva (Muguga) and five theilerial strains. Veterinary Parasitology $\mathrm{x}, 35-4 \mathrm{I}$. 
RICHARDS, G. M. (1974). Modifications of the diphenylamine reaction giving increased sensitivity and simplicity in the estimation of DNA. Analytical Biochemistry 57, 369-376.

Wagner, G. G., Brown, C. G. D., Duffus, W. P. H., Kimber, C. D., Crawford, J. G. \& Lule, M. (1974a). Immunochemical studies on East Coast fever: 1. Partial segregation and characterisation of the Theileria parva schizont antigen. Journal of Parasitology 60, 848-853.

WAGNeR, G. G., Duffus, W. P. H. \& BuRRIDGE, M. J. (I974b). The specific immunoglobulin response in cattle immunised with isolated Theileria parva antigens. Parasitology 69, 43-53.

Wagner, G. G., Duffus, W. P. H., Kimber, C. D. \& Lule, M. (I974c). Immunochemical studies on East Coast fever. II. Partial segregation and characterisation of the Theileria parva piroplasm antigen. Journal of Parasitology 60, 854-859.

Wagner, G. G., Duffus, W. P. H., AKwabi, C., Burridge, M. J. \& Lule, M. (1975). The specific immunoglobulin response in cattle to Theileria parva (Muguga) infection. Parasitology 70, 95-102. 